\title{
Effect of endovascular stenting of aortic coarctation on biventricular function in adults
}

\author{
Yat-Yin Lam, Mehmet G Kaya, Wei Li, Vaikom S Mahadevan, Arif A Khan, Michael Y Henein, \\ Michael Mullen
}

See end of article for authors' affiliations

Correspondence to Dr Y-Y Lam, Department of Echocardiography, Royal Brompton Hospital, Sydney Street, London, SW3 6NP,

UK; homalam@hotmail.com

Accepted 27 February 2007 Published Online First 13 June 2007

.......................

\begin{abstract}
Objective: To investigate the effect of endovascular stenting of aortic coarctation on biventricular function in adults during intermediate-term follow-up.

Methods: 21 patients (age 34 (10) years) were studied prospectively before and 14 (2) months after coarctation stenting from year 2002 to 2005. Biventricular function and blood pressure measurements were made. The post-stenting results were compared with pre-stenting values (group 1), with 22 age- and sexmatched post-surgical repair patients (group 2) and 30 normal controls (group 3).

Results: The peak systolic gradient across the coarctation site fell $(55(15) \mathrm{mm} \mathrm{Hg}$ to 18 (8) $\mathrm{mm} \mathrm{Hg}$, $p<0.001$ ). Systolic, mean blood pressure and left ventricular (LV) mass dropped after stenting ( $p<0.05$ for all). LV long-axis function improved at intermediate-term follow-up (tissue Doppler imaging lateral and septal systolic and diastolic velocities and E/Em ratios: $\mathrm{LSm}, 6.5(1.4) \mathrm{cm} / \mathrm{s}$ to $7.9(1.7) \mathrm{cm} / \mathrm{s} ; \mathrm{SSm}, 5.8(1.2) \mathrm{cm} / \mathrm{s}$ to $7.3(1.6) \mathrm{cm} / \mathrm{s} ; \mathrm{LEm}, 8.1(1.3)$ to $9.4(2.3) \mathrm{cm} / \mathrm{s} ; \mathrm{SEm}, 6.7(1.5) \mathrm{cm} / \mathrm{s}$ to $7.8(1.9) \mathrm{cm} / \mathrm{s} ; \mathrm{LE} / \mathrm{Em}, 11.2$ (2.7) to 9.8 (2.8); SE/Em, 14.8 (5.3) to 11.8 (3.9); $p<0.05$ for all). No significant difference in LV ejection fraction, conventional LV diastolic measurements (E, $A, E / A$ ratio, IVRT and DT) was found after stenting. No significant deterioration of right ventricular function was seen in stented patients. Both post-stenting and postsurgical repair patients had poorer LV long-axis function than controls ( $p<0.01$ for all).

Conclusions: Endovascular stenting of aortic coarctation resulted in medium-term LV mass regression and long-axis function improvement that may provide insight into long-term outcome of the stented patients. The results support aortic stenting in patients with anatomically suitable defects, given the additional benefit of avoiding cardiopulmonary bypass. The clinical significance of subclinical myocardial dysfunction in patients with stented or repaired coarctation warrants further studies.
\end{abstract}

S urvival of patients with aortic coarctation has dramatically improved since the availability of surgical repair in 1944. Despite apparently successful repair, these patients still have a lower life expectancy owing to premature cardiovascular diseases. ${ }^{1}$ Systemic hypertension and an increased left ventricular (LV) mass were important predictors of cardiovascular mortality and morbidities. ${ }^{2}$ Endovascular stenting of aortic coarctation has become a treatment option in adults with recurrent or native coarctation, with reported favourable outcomes in the early and intermediate follow-up periods over the past decade. ${ }^{3-6}$ The effect of endovascular stenting on ventricular function, however, has remained unknown. We and others have shown that LV long-axis function, which represents the subendocardium, is significantly impaired in patients undergoing aortic stenosis. ${ }^{78}$ Its potential for the regular assessment and monitoring of subendocardial behaviour in aortic coarctation patients has not yet been examined. Endovascular stenting that obviates the need for a cardiopulmonary bypass might further preserve right ventricular (RV) function compared with its surgical counterparts. This study thus aimed at evaluating the effect of endovascular stenting of aortic coarctation on biventricular function in adults.

\section{PATIENTS AND METHODS}

\section{Patient group}

We prospectively studied 21 consecutive patients referred to the Royal Brompton Hospital for endovascular stenting between October 2002 and January 2005. All patients had reduced femoral pulses and Doppler echocardiographic evidence of significant coarctation of the aorta by the criteria we previously reported. ${ }^{9}$ Informed consent was obtained from all patients and the study was approved by our local ethics committee. The "stented" group (group 1) results were then compared with two other groups: group 2 comprising 22 consecutive postsurgical repair patients with no clinical evidence of recoarctation; group 3 comprising 30 age- and sex-matched healthy volunteers from the hospital.

Apart from clinical examinations and cardiac catheterisations, patients receiving stenting, were echocardiographically studied and their right arm systolic, diastolic and mean blood pressures were measured supine using standard mercury sphygmomanometers at baseline and at 12 months after the procedure, according to the study protocol. Patients were defined as being hypertensive if they had blood pressure readings of greater than $140 / 90 \mathrm{~mm} \mathrm{Hg}$ on more than one occasion at rest. History of antihypertensive drug use was recorded and no adjustment of drugs was allowed 12 weeks before stenting. If patients were normotensive during the 1year follow-up assessment, tailing down of drugs was attempted.

Patients with suboptimal echocardiographic windows, pacemakers, prosthetic valves, associated hypoplastic LV and other haemodynamically significant valvular lesions were excluded from the study.

\section{Implantation procedure}

All procedures were performed under general anaesthesia and patients received $3000-5000 \mathrm{U}$ of heparin for anticoagulation

Abbreviations: LV, left ventricular; RV, right ventricular; SPG, systolic pressure gradient; TDI, tissue Doppler imaging; IVT, total isovolumic time 
Table 1 Patients' characteristics

\begin{tabular}{|c|c|c|c|}
\hline & Group 1 & Group 2 & Group 3 \\
\hline Variables & $\begin{array}{l}\text { Pre- and } \\
\text { post- } \\
\text { stenting } \\
(n=21)\end{array}$ & $\begin{array}{l}\text { Post- } \\
\text { surgical } \\
\text { repair } \\
(n=22)\end{array}$ & $\begin{array}{l}\text { Control } \\
(n=30)\end{array}$ \\
\hline \multicolumn{4}{|l|}{ Demographics } \\
\hline Age (years), mean (SD) & $34(10)$ & $35(13)$ & $36(10)$ \\
\hline $\operatorname{Sex}(M / F)$ & $11 / 10$ & $11 / 11$ & $17 / 13$ \\
\hline Heart rate (bpm), mean (SD) & $68(10)$ & $67(8)$ & $67(10)$ \\
\hline Bicuspid aortic valve, No (\%) & $10(48)$ & $10(45)$ & \\
\hline \multicolumn{4}{|l|}{ Treatment history } \\
\hline \multicolumn{4}{|l|}{ Coarctation history } \\
\hline Native, No (\%) & $13(62)$ & & \\
\hline Previous surgical repair, No (\%) & $8(38)$ & $22(100)^{*}$ & \\
\hline $\begin{array}{l}\text { Age at time of repair (months), } \\
\text { mean (IQR) }\end{array}$ & $24(6-54)$ & $24(9-126)$ & \\
\hline Age at time of stenting (years), & & & \\
\hline & $30(11)$ & & \\
\hline $\begin{array}{l}\text { mean (SD) } \\
\text { History of cardiopulmonary bypass, }\end{array}$ & $14(2)$ & & \\
\hline No $(\%)$ & $3(14)$ & $14(64) \dagger$ & \\
\hline \multicolumn{4}{|l|}{ Stents } \\
\hline Palmaz, No (\%) & $7(33)$ & & \\
\hline CP Numed, No (\%) & $9(43)$ & & \\
\hline Sinus-aortic, No (\%) & $5(24)$ & & \\
\hline
\end{tabular}

during the procedure. The Palmaz (Johnson \& Johnson Interventional Systems Co, Warren, New Jersey, USA), CP Numed (NuMED, Hopkinton, New York, USA) and sinus-Aorta (Optimed, Ettlingen, Germany) stents were used according to the operator's preference. All patients received primary stenting (ie, stenting without predilatation). Stents with lengths varying from 26 to $46 \mathrm{~mm}$ were implanted with techniques previously described. ${ }^{6}{ }^{10}$ Peak to peak pressure gradients across coarctation sites were recorded at baseline and during intermediateterm follow-up.

\section{Echocardiographic examination}

Echocardiographic images were obtained according to the guidelines of the American Society of Echocardiography ${ }^{12}$ with an Agilent Sonos 2500 and 5500 system (Hewlett Packard, Palo Alto, California, USA). At lease three consecutive beats in sinus rhythm were recorded, and the average values were taken. The LV end-diastolic and end-systolic dimensions (LVEDD and LVESD), end-diastolic and end-systolic interventricular septal and posterior wall thickness (IVSd; IVSs and LPWd; LPWs) were measured from M-mode recordings of the LV cavity with the cursor by the tip of the mitral valve leaflets in the parasternal long-axis view, and LV ejection fraction and fractional shortening were calculated accordingly. The LV mass was calculated using the Devereux formula. ${ }^{13}$ Left ventricular end-systolic meridional wall stress (WS) was calculated from $\mathrm{M}$-mode data in combination with systolic blood pressure data, using the following formula:

$\mathrm{WS}=0.334 \times \mathrm{P} \times \mathrm{LVESD} /(\mathrm{LPWs} \times(1+\mathrm{LPWs} / \mathrm{LVESD}))^{14} 15$ where $\mathrm{P}=$ systolic blood pressure, LVESD $=$ LV end-systolic dimension and LPWs $=\mathrm{LV}$ end-systolic posterior wall thickness.

Ventricular long-axis motion was recorded from the lateral, septal and tricuspid angles of the atrioventricular junction by M-mode and pulsed-wave tissue Doppler imaging (TDI) techniques. ${ }^{16}$ Long-axis systolic amplitude was measured as previously reported. ${ }^{17}$ Myocardial Doppler signal quality was enhanced by decreasing the Doppler sample volume size to $<5 \mathrm{~mm}$, adjusting the Nyquist limit to $10-30 \mathrm{~cm} / \mathrm{s}$, using the lowest wall filter setting with minimal gain and optimising the sweep speed to at least $100 \mathrm{~mm} / \mathrm{s}$. Peak long-axis TDI velocities were measured from the middle part of the recorded velocity envelope. ${ }^{16}$

Continuous-wave Doppler recordings were obtained from the suprasternal view to measure the maximal velocity (V) across the coarctation site. Peak systolic pressure gradients (peak SPG) were calculated using the simplified Bernoulli equation (peak SPG $=4 \mathrm{~V}^{2}$ ). The presence of a diastolic tail was documented if there was antegrade flow in the descending aorta during diastole. Diastolic velocity $(\mathrm{cm} / \mathrm{s})$ was measured at the end of the T wave on the ECG tracing, as previously described. ${ }^{9}$ Pulsedwave Doppler was applied to record the flow in the abdominal aorta from a standard subcostal view. A $2 \mathrm{~mm}$ size sample volume of pulsed-wave Doppler was placed at the tip of the mitral leaflets to record transmitral Doppler velocities. Peak early LV filling velocity (E), peak atrial filling velocity (A), E/A ratio, E wave deceleration time (DT) and isovolumic relaxation time (IVRT) were measured from the LV filling recordings. Total LV isovolumic time (tIVT) was calculated as the sum of the total filling and ejection times subtracted from the R-R interval. ${ }^{18}$ The LV myocardial performance index was calculated as the tIVT divided by ejection time. ${ }^{19}$ All echocardiographic measurements were carried out by two experienced observers who were unaware of the clinical data.

\section{Reproducibility of the measurements}

Intraobserver and interobserver variability was assessed in 14 randomly chosen patients. Variability was calculated as the mean percentage error, derived as the difference between two sets of measurements, divided by the mean of the observations.

\begin{tabular}{|c|c|c|c|c|}
\hline & Group 1 & Group 1 & Group 2 & Group 3 \\
\hline Variables & $\begin{array}{l}\text { Pre-stenting } \\
(n=21)\end{array}$ & $\begin{array}{l}\text { Post-stenting } \\
(n=21)\end{array}$ & $\begin{array}{l}\text { Post surgical } \\
\text { repair } \\
\text { (n=22) }\end{array}$ & $\begin{array}{l}\text { Control } \\
(n=30)\end{array}$ \\
\hline $\begin{array}{l}\text { Hypertension, No (\%) } \\
\text { Blood pressure (mm Hg) }\end{array}$ & $15 / 21(71)$ & & $7 / 22(32)^{*}$ & $0 / 30(0) \dagger$ \\
\hline $\begin{array}{l}\text { Systolic, mean (SD) } \\
\text { Diastolic, mean (SD) } \\
\text { Mean (SD) }\end{array}$ & $\begin{array}{l}147(21) \\
77(13) \\
100(12)\end{array}$ & $\begin{array}{l}135(16)^{*} \\
73(10) \\
93(9)^{*}\end{array}$ & $\begin{array}{l}132(13) \dagger \\
75(8) \\
96(10)\end{array}$ & $\begin{array}{l}128(10)+ \\
70(8) \\
89(9)^{*}\end{array}$ \\
\hline $\begin{array}{l}\text { Antihypertensive drug use at } 1 \text { year } \\
\text { Drug number reduction, No (\%) } \\
\text { Dose reduction, No (\%) } \\
\text { No of drugs per patients, mean (SD) }\end{array}$ & $1.5(0.6)$ & $\begin{array}{l}1 / 15(7) \\
3 / 15(20) \\
1.4(0.5)\end{array}$ & $1.3(0.5)$ & \\
\hline
\end{tabular}


Table 3 Evaluation for CoA severity

\begin{tabular}{|c|c|c|c|}
\hline \multirow[b]{2}{*}{ Variables } & \multirow{2}{*}{$\begin{array}{l}\text { Group } 1 \\
\begin{array}{l}\text { Pre-stenting } \\
(n=21)\end{array}\end{array}$} & \multirow{2}{*}{$\begin{array}{l}\text { Group 1 } \\
\begin{array}{l}\text { Post-stenting } \\
\text { (n=21) }\end{array}\end{array}$} & \multirow{2}{*}{$\begin{array}{l}\text { Group } 2 \\
\text { Post-surgical repair } \\
(\mathrm{n}=22)\end{array}$} \\
\hline & & & \\
\hline \multicolumn{4}{|l|}{$\begin{array}{l}\text { Echocardiographic } \\
\text { CW Doppler CoA site }\end{array}$} \\
\hline Peak SPG (mm Hg), mean (SD) & $55(15)$ & $18(8)^{*}$ & $17(7)^{*}$ \\
\hline Diastolic tail, No (\%) & $16 / 21(76)$ & $0 / 21(0)^{*}$ & $0 / 22(0)^{*}$ \\
\hline Diastolic velocity $(\mathrm{cm} / \mathrm{s})$, mean (SD) & $242(39)(n=16)$ & NA & NA \\
\hline \multicolumn{4}{|l|}{ PW Doppler abdominal aorta } \\
\hline Abdominal aortic continuous flow, No (\%) & $18 / 21(86)$ & $1 / 21(5)^{*}$ & $1 / 22(5)^{*}$ \\
\hline $\begin{array}{l}\text { Cardiac catheterisation } \\
\text { Peak to peak gradient }(\mathrm{mm} \mathrm{Hg}) \text {, mean (SD) }\end{array}$ & $43(10)$ & $12.1(8.2)^{\star}$ & \\
\hline
\end{tabular}

\section{Statistics}

All statistics were processed by designated software (SPSS 11). For each of the measured variables, values were expressed as mean (SD) or median and range according to the data distribution. Comparisons of pre- and post-stenting variables were made using the two-tailed paired Student $t$ test. Differences between various study groups were evaluated by one-way analysis of variance. When the analysis of variance was significant, variables between groups were compared using the unpaired Student $t$ test or Mann-Whitney $U$ test as appropriate. Categorical variables were presented as absolute values and percentages, and comparisons were tested by the $\chi^{2}$ test. A value of $p \leqslant 0.05$ and $p \leqslant 0.01$ were considered significant and highly significant, respectively.

\section{RESULTS}

\section{Demographics}

Table 1 summarises the clinical data. There was no significant difference between age, gender and heart rate in the two patient groups and the controls. Group 1 comprised 21 patients (age 34 (10) years, 11 men; 48\% with bicuspid aortic valve) who had stenting for recurrent $(n=8)$ and native $(n=13)$ coarctation. The Palmaz, CP Numed and sinus-Aortic stents were used in seven, nine and five patients, respectively. Group 2 comprised 22 patients (age 35 (13) years, 11 men; 45\% with bicuspid aortic valves) who had previous surgical repair (median age of repair 24 months, interquartile range 9126 months) without clinical evidence of recurrent coarctation. Cardiopulmonary bypass was more prevalent in group 2 than in group 1 ( $64 \%$ vs $14 \%, p=0.002)$. Group 3 comprised 30 healthy volunteers (age 36 (10) years; 17 men).

\section{Blood pressure data}

Table 2 shows blood pressure data.

Fifteen patients were receiving antihypertensive drugs before endovascular stenting. There was a significantly higher prevalence of systemic hypertension in post-stenting compared with post-surgical repair patients ( $71 \%$ vs $32 \%$; $<<0.05)$. Their systolic, diastolic and mean blood pressures were not statistically different at the time of study, probably owing to the concomitant use of antihypertensive drugs.

Table 4 Global left ventricular (LV) function

\begin{tabular}{|c|c|c|c|c|}
\hline & Group 1 & Group 1 & Group 2 & Group 3 \\
\hline & $\begin{array}{l}\text { Pre-stenting } \\
(n=21)\end{array}$ & $\begin{array}{l}\text { Post-stenting } \\
(n=21)\end{array}$ & $\begin{array}{l}\text { Post-surgical } \\
\text { repair } \\
(\mathrm{n}=22 \text { ) }\end{array}$ & $\begin{array}{l}\text { Control } \\
(n=30)\end{array}$ \\
\hline \multicolumn{5}{|l|}{ LV structure and systolic function } \\
\hline LV end-diastolic diameter (mm) & $51(9)$ & $51(8)$ & $49(6)$ & $47(6)$ \\
\hline LV end-systolic diameter (mm) & $32(6)$ & $29(6)$ & $29(6)$ & $28(4)$ \\
\hline Interventricular septal thickness (mm) & 12 (3) & $11(3)^{*}$ & $11(2)^{*}$ & $9(2)^{*} \dagger$ \\
\hline LV posterior wall thickness $(\mathrm{mm})$ & $12(3)$ & $10(2)^{*}$ & $10(2)^{*}$ & $9(1)^{*}$ \\
\hline LV fractional shortening $(\%)$ & $42(7)$ & $42(7)$ & $38(8)$ & $37(6)$ \\
\hline LV ejection fraction (\%) & 7417 & $75(8)$ & $70(9)$ & $72(7)$ \\
\hline $\mathrm{LV}$ mass $(\mathrm{g})$ & $257.6(117.8)$ & $212.2(70.9)^{*}$ & $195.7(59.3)^{*}$ & $155.4(57.8)^{*} \dagger$ \\
\hline LV end-systolic wall stress $\left(10^{3}\right.$ dynes $\left./ \mathrm{cm}^{2}\right)$ & $106(12)$ & $79(10)^{*}$ & $77(9)^{*}$ & $69(8)^{*}$ \\
\hline \multicolumn{5}{|l|}{ LV diastolic function } \\
\hline Mitral $\mathrm{E}(\mathrm{cm} / \mathrm{s})$ & $90(21)$ & $89(20)$ & $87(17)$ & $69(14)^{*} \dagger$ \\
\hline$A(\mathrm{~cm} / \mathrm{s})$ & $61(17)$ & $59(12)$ & $56(14)$ & $49(13)$ \\
\hline $\mathrm{E} / \mathrm{A}$ & $1.6(0.4)$ & $1.5(0.3)$ & $1.5(0.4)$ & $1.5(0.4)$ \\
\hline Deceleration time (DT) (ms) & $219(39)$ & $212(36)$ & $213(28)$ & $199(29)$ \\
\hline Isovolumic relaxation time (IVRT) (ms) & $66(11)$ & $64(9)$ & $61(13)$ & $65(15)$ \\
\hline \multicolumn{5}{|l|}{ LV global indices } \\
\hline LV MPI & $0.28(0.06)$ & $0.28(0.04)$ & $0.27(0.06)$ & $0.24(0.07)$ \\
\hline LV HIVT (s/min) & $9.5(0.6)$ & $9.4(0.5)$ & $9.2(0.5)$ & $8.6(0.7)$ \\
\hline
\end{tabular}

Results are shown as mean (SD).

$\mathrm{MPI}$, myocardial performance index; $\mathrm{IIVT}$, total LV isovolumic time.

${ }^{*} \mathrm{p}<0.05$ vs pre-stenting; $\mathrm{t} \mathrm{p}<0.05$ vs post-stenting and post-surgical repair. 
Table 5 Segmental ventricular function

\begin{tabular}{|c|c|c|c|c|}
\hline & \multirow{2}{*}{$\begin{array}{l}\text { Group } 1 \\
\begin{array}{l}\text { Pre-stenting } \\
(n=21)\end{array}\end{array}$} & \multirow{2}{*}{$\begin{array}{l}\text { Group } 1 \\
\begin{array}{l}\text { Post-stenting } \\
(n=21)\end{array}\end{array}$} & \multirow{2}{*}{$\begin{array}{l}\text { Group } 2 \\
\text { Post-surgical } \\
\text { repair } \\
(\mathrm{n}=22)\end{array}$} & \multirow{2}{*}{$\begin{array}{l}\text { Group } 3 \\
\begin{array}{l}\text { Control } \\
(n=30)\end{array}\end{array}$} \\
\hline & & & & \\
\hline \multicolumn{5}{|l|}{ LV lateral site } \\
\hline Amplitude $(\mathrm{cm})$, LSA & $1.2(0.2)$ & $1.3(0.2)^{*}$ & $1.3(0.1)^{*}$ & $1.6(0.2) \dagger \ddagger$ \\
\hline \multicolumn{5}{|l|}{ Velocities $(\mathrm{cm} / \mathrm{s})$} \\
\hline $\mathrm{Sm}$ & $6.5(1.4)$ & $7.9(1.7) \dagger$ & $7.8(1.7) \dagger$ & $10.3(1.9) \dagger \ddagger$ \\
\hline $\mathrm{Em}$ & $8.1(1.3)$ & $9.4(2.3)^{*}$ & $9.6(2.8)^{*}$ & $12.7(3.0) \dagger \ddagger$ \\
\hline \multicolumn{5}{|l|}{ Ratio } \\
\hline $\mathrm{E} / \mathrm{Em}$ & $11.2(2.7)$ & $9.8(2.8)^{*}$ & $9.3(3.4)^{*}$ & $5.7(1.7) \dagger \ddagger$ \\
\hline \multicolumn{5}{|l|}{ Septal site } \\
\hline \multirow{2}{*}{\multicolumn{5}{|c|}{ Velocities $(\mathrm{cm} / \mathrm{s})$}} \\
\hline & & & & \\
\hline $\mathrm{Sm}$ & $5.8(1.2)$ & $7.3(1.6) \dagger$ & $7.2(1.2) \dagger$ & $8.6(1.0) \dagger \ddagger$ \\
\hline $\mathrm{Em}$ & 6.7 (1.5) & $7.8(1.9)^{\star}$ & $7.5(1.0) \dagger$ & $10.0(2.4) \dagger \ddagger$ \\
\hline \multicolumn{5}{|l|}{ Ratio } \\
\hline $\mathrm{E} / \mathrm{Em}$ & $14.8(5.3)$ & $11.8(3.9) \dagger$ & $11.1(3.0) \dagger$ & $7.0(1.8) \dagger \ddagger$ \\
\hline \multicolumn{5}{|l|}{$R V$ free wall site } \\
\hline Amplitude $(\mathrm{cm})$, RSA & $2.2(0.4)$ & $2.2(0.5)$ & $2.1(0.4)$ & $2.3(0.2) \S$ \\
\hline \multicolumn{5}{|l|}{ Velocities $(\mathrm{cm} / \mathrm{s}$ ) } \\
\hline $\mathrm{Sm}$ & $11.7(1.8) \S$ & $12.0(1.4) \S$ & $10.5(1.5)$ & $12.4(1.8) \S$ \\
\hline $\mathrm{Em}$ & $10.8(3.1)$ & $11.2(3.4)$ & $10.5(3.4)$ & $10.9(3.0)$ \\
\hline
\end{tabular}

The systolic and mean blood pressures fell from 147 (21) mm $\mathrm{Hg}$ to 135 (16) $\mathrm{mm} \mathrm{Hg}$ and 100 (12) $\mathrm{mm} \mathrm{Hg}$ to 93 (9) $\mathrm{mm} \mathrm{Hg}$, respectively, after endovascular stenting $(\mathrm{p}<0.05$ for both). There was a non-significant drop in diastolic blood pressure. One patient $(7 \%)$ had the number of antihypertensive drugs reduced and three other patients had the dosage of drugs reduced during the 1-year follow-up (20\%). A non-significant decrease in mean number of drugs per patient was seen. (1.5 (0.6) to $1.4(0.5) ; \mathrm{p}=0.32)$

\section{Echocardiographic data}

Pre-stenting versus post-stenting (group 1)

The time interval between endovascular stenting and echocardiographic examination was 14 (2) months. The peak SPG across the coarctation site fell from 55 (15) $\mathrm{mm} \mathrm{Hg}$ to 18 (8) $\mathrm{mm} \mathrm{Hg}(\mathrm{p}=0.001)$ (table 3$)$. Catheter-derived peak to peak

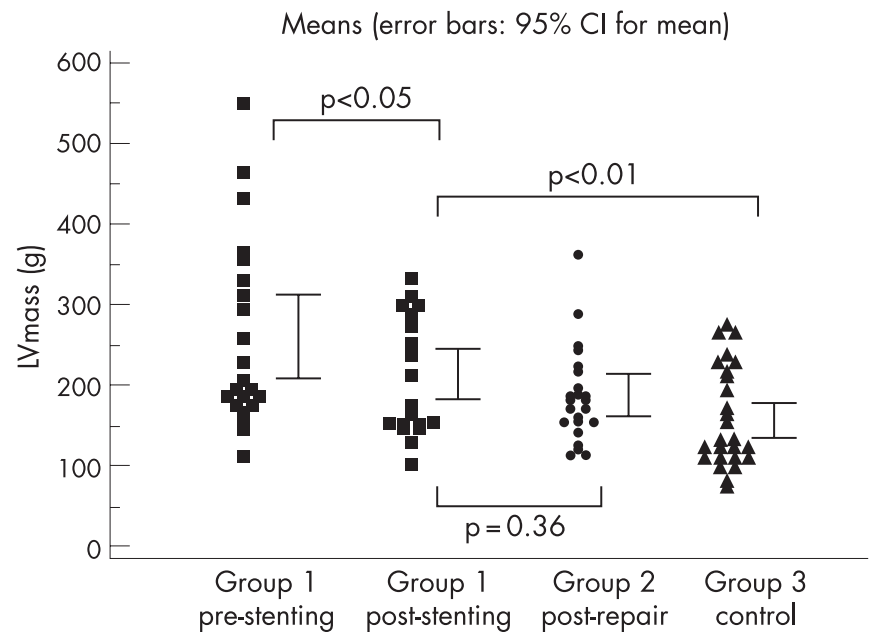

Figure 1 Diagram comparing left ventricular (LV) mass between poststenting, post-surgical repair and normal control groups. pressure gradients showed a similar trend to the Doppler echocardiographic findings $(43$ (10) $\mathrm{mm} \mathrm{Hg}$ to 12.1 (8.2) $\mathrm{mm}$ $\mathrm{Hg} ; \mathrm{p}=0.001)$. A significant decrease in the percentage of diastolic tail and restoration of pulsatile abdominal aortic flow measured by pulsed-wave Doppler was seen (all $\mathrm{p}=0.001$ ). There was no significant change in LV dimensions, but patients had thinner interventricular septal and posterior walls, and consequently lower LV masses (257.6 (117.8) g to 212.2 (70.9) g), after the procedure $(p<0.05$ for all). The LV endsystolic meridional wall stress, which has been validated as an accurate non-invasive surrogate to assess the severity of $\mathrm{LV}$ pressure overload, ${ }^{14}{ }^{15}$ also decreased after stenting ( 106 (12) to 79 (10) $10^{3}$ dynes $/ \mathrm{cm}^{2} ; \mathrm{p}<0.05$ ) (table 4 ).

No significant difference was noted in LV minor axis fractional shortening, ejection fraction, conventional LV diastolic measurements (E, A, E/A ratio, IVRT and DT) or global indices measured by either myocardial performance index or tIVT.

LV long-axis function improved after stenting (table 5). LV lateral (LSA) and septal (SSA) long-axis systolic amplitudes increased after the procedure $(p=0.04$ and $p=0.002$, respectively). The change of long-axis TDI systolic velocities (LSm and

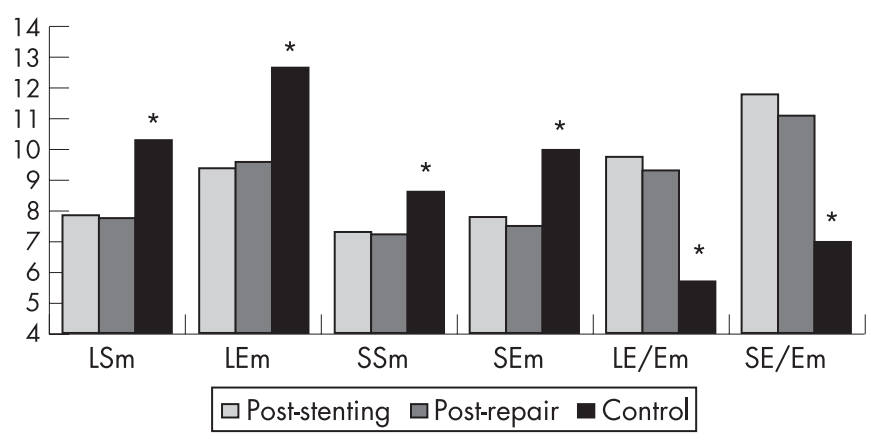

Figure 2 Diagram comparing left ventricular long-axis function between post-stenting, post-surgical repair and normal control groups. 
SSm) echoed findings for the systolic amplitudes $(\mathrm{p}<0.01$ for all). The diastolic velocities (LEm and SEm) increased and E/ Em ratios (LE/Em and SE/Em) decreased significantly $(p<0.05$ for all).

\section{Stenting (group 1) versus post-surgical repair (group 2)}

Post-surgical repair patients had a similar peak SPG to poststenting patients (18 (8) $\mathrm{mm} \mathrm{Hg}$ vs 17 (7) mm Hg, p=0.98; table 3 ). Both patients groups also had similar LV mass and long-axis function. No deterioration of RV function was seen in patients after receiving stenting (RSA $2.2(0.4) \mathrm{cm}$ to 2.2 $(0.5) \mathrm{cm}$, TSm 11.7 (1.8) to 12.0 (1.4) cm/s, p $>0.30$ for both). Post-surgical repair patients, however, had poorer RV long-axis function, as reflected by significantly lower RV free wall systolic velocities compared with pre- and post-stenting patients (TSm $11.7(1.8) \mathrm{cm} / \mathrm{s}$ and $12.0(1.4) \mathrm{cm} / \mathrm{s}$ vs $10.5(1.5) \mathrm{cm} / \mathrm{s}$, both $\mathrm{p}<0.05$ ) (table 5).

\section{Coarctation patients (group 1 post-stenting and group} 2) versus control (group 3)

Figure 1 illustrates significantly higher LV masses in poststenting and post-surgical repair patients than in normal controls $(\mathrm{p}<0.01)$. Coarctation patients also had higher LV early filling velocities (E), lower long-axis systolic amplitudes and velocities, and higher $E / E m$ ratios than controls $(p<0.01$ for all) (fig 2).

\section{Reproducibility}

Intraobserver and interobserver variability for conventional Doppler and TDI derived variables (IVSd, LPWd, Sm, Em) ranged from $2 \%$ to $8 \%$. Reproducibility of long-axis measurements has previously been published. ${ }^{16}$

\section{DISCUSSION}

Our study examined the improvement in LV long-axis systolic and diastolic function with preservation of RV long-axis function during intermediate-term follow-up of patients receiving endovascular stenting of aortic coarctation. We also demonstrated the presence of subclinical LV dysfunction in stented and surgically repaired patients compared with normal controls.

\section{Potential impact of stenting on cardiovascular outcome} Surgically repaired coarctation patients had higher mortality and morbidity than the normal population owing to a higher risk for developing cardiovascular complications. ${ }^{1}$ Hypertension and an increase in LV mass were important and independent predictors of outcome. ${ }^{2}$ Although endovascular stenting has become a standard treatment option in selected adults with reported favourable early and intermediate-term safety and efficacy data, little is known about LV mass changes that might shed light on long-term cardiovascular outcomes.

\section{BP control}

Long-term follow-up studies in adolescent patients with balloon angioplasty demonstrated a $63-79 \%$ regression of hypertension. ${ }^{20}{ }^{21}$ Data were especially scant for blood pressure control in adults. We previously reported an improvement in 24-hour ambulatory systolic blood pressure readings 6 weeks after stenting. ${ }^{6}$ This study demonstrated an $8 \%$ and $7 \%$ significant reduction in systolic and mean blood pressure, respectively, and during a follow-up of 14 (2) months. Of hypertensive coarctation patients, $7 \%$ and $20 \%$ were able to reduce the number and the dosage of drugs, respectively. The findings confirmed the sustained benefit effect of stenting on blood pressure control in adult patients at medium-term follow-up.
LV mass and long-axis function

We observed an LV mass regression after endovascular stenting. Studies in patients with severe aortic valvular stenosis have shown that the majority of LV mass regression occurred in the first 6 months after aortic valve replacement. ${ }^{22}$ Thus our measurements obtained from an average of 14 months after intervention probably represent a fairly established LV remodelling process given the similar nature of chronic increase in LV outflow resistance in the two conditions. The LV masses of the post-stenting patients regressed to a degree comparable to those observed in post-surgical repaired patients (fig 1).

Our findings therefore illustrated the selective sensitivity of LV long-axis function, which we previously reported in aortic stenotic patients, ${ }^{7}$ for detecting and monitoring myocardial function in coarctation patients as well. Since all our studied patients were asymptomatic, our data probably represent an improvement of subclinical myocardial dysfunction in view of the relative load independence of TDI velocities ${ }^{23}$ and the established accuracy of the E/Em ratio in predicting LV filling pressure in aortic stenosis. ${ }^{8}$ LV long-axis function, which represents the subendocardium, was found to be impaired in patients with LV hypertrophy secondary to chronic increase in outflow resistance ${ }^{8}$ because of myocardial fibrosis ${ }^{24}$ or subendocardial ischaemia, ${ }^{25}$ or both. A lower post-stenting LV mass together with a fall in LV afterload (reflected by a decrease in LV end-systolic wall stress) ameliorated myocardial work and subsequently resulted in a better LV long-axis function at intermediate-term follow-up.

\section{RV function after stenting}

Previous studies have demonstrated tricuspid long-axis annular motion as a surrogate marker for global RV function. ${ }^{26}{ }^{27}$ Our data showed that RV long-axis function was poorer in postsurgical repair patients than in even pre-stenting patients. This might be attributed to the higher prevalence of cardiopulmonary bypass in the post-surgical repair group $(p=0.002)$. Studies have reported significant impairment of RV function after cardiopulmonary bypass for coronary artery bypass grafting ${ }^{28}$ and aortic valve replacement. ${ }^{29}$ We have previously documented the preservation of RV long-axis function after transcatheter closure of secundum atrial septal defects compared with its surgical counterpart. ${ }^{30}$ In the current study we reported no significant deterioration of RV function in patients receiving stenting. Endovascular stenting, which avoids cardiopulmonary bypass, probably contributes to the preservation of RV function. In view of the reduced morbidity associated with an endovascular approach, we suggest that aortic stenting should be used in anatomically suitable defects, particularly for those recurrent lesions after previous surgical repair. However, native coarctation data are still being gathered looking into the long-term morbidities of surgical repair in comparison with endovascular stenting-for example, the incidence of aortic aneurysms. ${ }^{31}$

\section{Subclinical LV myocardial dysfunction in coarctation patients}

Our study also demonstrated that patients with coarctation, despite successful "correction" by endovascular or surgical means, still had significantly higher LV masses and subclinical long-axis myocardial dysfunction than controls (figs 1 and 2). These "corrected" patients have reduced LV long-axis velocities and higher E/Em ratios than normal controls. They also had higher early LV filling velocities (E), which indicated a higher LA-LV pressure gradient during early diastole. The finding of a higher LV mass and subclinical myocardial dysfunction in patients without significant re-coarctation suggested an increase in LV pressure afterload due to other mechanisms. First, longstanding hypertension in these patients inadvertently 


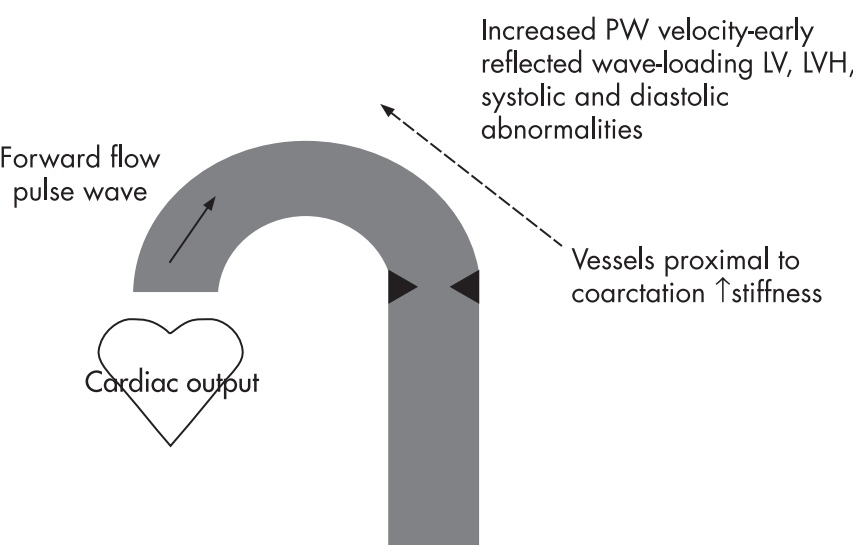

Figure 3 Schematic diagram illustrating a possible mechanism of subclinical myocardial dysfunction in "corrected" coarctation.

posed some damage to the LV myocardium. In addition, such a finding supported the theory that coarctation of the aorta itself is not simply a focal lesion but a complex interplay of loss of vascular compliance proximal to obstruction, abnormal neurohormonal activation and, possibly, genetically programmed arteriopathy. ${ }^{32}$

A few studies have examined proximal arteriopathy by demonstrating arterial stiffness ${ }^{33}{ }^{34}$ and endothelial dysfunction ${ }^{35}$ in young patients with previous coarctation repair. An enhanced aortic pressure wave reflection ${ }^{36}$ secondary to aortic stiffness probably leads to an increase in LV afterload and contributes to subsequent LV hypertrophy and subclinical myocardial dysfunction (fig 3). Treatment strategies targeted at proximal vascular compliance in "corrected" coarctation patients might further improve their long-term clinical outcomes.

\section{Limitations}

Our study had several potential limitations. First, we reported LV mass and LV long-axis function changes at 1 year follow-up only. Studies in patients with aortic stenosis, however, have shown that most LV mass regression occurred in the first 6 months after aortic valve replacement. ${ }^{22}$ Thus our echocardiographic studies an average of 14 months after intervention probably represented a fairly established LV remodelling process. Second, the duration of follow-up was variable and data regarding pre-interventional disease severity between post-stenting and post-surgical repair patients were scarce. The current study was primarily designed to evaluate the effect of endovascular stenting on ventricular function in adults. We included the post-surgical cohort to illustrate subclinical myocardial dysfunction in both stented and post-surgical repair patients as compared with normal controls. It would be inappropriate to draw any solid conclusion for the difference in LV function between the two patient groups or to claim superiority of a particular treatment approach based on current data. Furthermore, we used M-mode measurement of LV mass, which in numerous previous publications has been reported to be linked to adverse outcomes in large epidemiological studies. ${ }^{38}$ New imaging modalities like cardiac magnetic resonance imaging ${ }^{39}$ or three-dimensional echocardiography might provide more precise and reproducible assessment. Lastly, this was a small, single-centre study and a large multicentre study would be welcomed to validate our findings further.

\section{CONCLUSION}

Endovascular stenting of aortic coarctation resulted in LV mass regression and improvement in LV long-axis function that may provide insight into long-term cardiovascular prognosis. Our findings support aortic stenting in patients with anatomically suitable defects, given the additional benefit of avoiding cardiopulmonary bypass. The clinical significance of subclinical myocardial dysfunction in patients with "corrected" coarctation should be examined in future studies.

\section{ACKNOWLEDGEMENTS}

Dr Yat-Yin Lam was supported by Hong Kong Hospital Authority. We are grateful for the support received from adult patients with congenital heart disease, and staff at the Royal Brompton Hospital. We also thank Dr Gabriel WK Yip for his statistical assistance, and Miss Hidi HT Lee for her generous secretarial support.

\section{Authors' affiliations \\ Yat-Yin Lam, Division of Cardiology, SH Ho Cardiovascular and Stroke Centre, Department of Medicine and Therapeutics, Prince of Wales Hospital, The Chinese University of Hong Kong, Hong Kong \\ Mehmet G Kaya, Vaikom S Mahadevan, Arif A Khan, Michael Mullen, Adult Congenital Heart Unit, Royal Brompton Hospital, London, UK Wei Li, Department of Echocardiography, Royal Brompton Hospital, London, UK \\ Michael Y Henein, Department of Cardiology, West Middlesex University Hospital, London, UK \\ Funding: Dr Yat-Yin Lam was supported by Hong Kong Hospital Authority. Conflict of interest: None.}

\section{REFERENCES}

1 Cohen M, Fuster V, Steele PM, et al. Coarctation of the aorta. Long-term followup and prediction of outcome after surgical correction. Circulation 1989;80:840-5.

2 de Divitiis M, Pilla C, Kattenhorn M, et al. Ambulatory blood pressure, left ventricular mass, and conduit artery function late after successful repair of coarctation of the aorta. J Am Coll Cardiol 2003;41:2259-65.

3 Toro-Salazar OH, Steinberger J, Thomas W, et al. Long-term follow-up of patients after coarctation of aorta repair. Am J Cardiol 2002;89:541-5.

4 Ebeid MR, Prieto LR, Latson LA. Use of balloon-expandable stents for coarctation of aorta: initial results and intermediate long-term follow up. J Am Coll Cardiol 1997;30:1847-52.

5 Marshall AC, Perry SB, Keane JF, et al. Early results and medium-term follow- up of stent implantation for mild residual or recurrent coarctation. Am Heart $J$ 2000;139:1054-60.

6 Mahadevan VS, Vondermuhll IF, Mullen MJ. Endovascular aortic coarctation stenting in adolescents and adults: angiographic and hemodynamic outcomes. Catheter Cardiovasc Interv 2006:67:268-75.

7 Lam YY, Kaya MG, Goktekin O, et al. "Isolated" diastolic dysfunction in left ventricular outflow tract obstruction. Am J Cardiol 2006;98:509-14.

8 Bruch C, Stypmann J, Grude M, et al. Tissue Doppler imaging in patients with moderate to severe aortic valve stenosis: clinical usefulness and diagnostic accuracy. Am Heart J 2004;148:696-702.

9 Tan JL, Babu-Narayan SV, Henein MY, et al. Doppler echocardiographic profile and indexes in the evaluation of aortic coarctation in patients before and after stenting. J Am Coll Cardiol 2005;46:1045-53.

10 Magee AG, Brzezinska-Rajszys G, Qureshi SA, et al. Stent implantation for aortic coarctation and recoarctation. Heart 1999;82:600-6.

11 Harrison DA, McLaughlin PR, Lazzam C, et al. Endovascular stents in the management of coarctation of the aorta in the adolescent and adult: one year follow up. Heart 2001;85:561-6.

12 Schiller NB. Two-dimensional echocardiographic determination of left ventricular volume, systolic function, and mass. Summary and discussion of the 1989 recommendations of the American Society of Echocardiography. Circulation $1991 ; 84$ (suppl I):I280-7.

13 Devereux RB. Detection of left ventricular hypertrophy by $\mathrm{M}$-mode echocardiography: anatomical validation, standardization, and comparison to other methods. Hypertension 1987;9(suppl II):II-19-26.

14 Reichek N, Wilson J, St John Sutton M, et al. Noninvasive determination of left ventricular end-systolic stress: validation of the method and initial application. Circulation 1982;65:99-108.

15 Douglas PS, Reichek N, Plappert T, et al. Comparison of echocardiographic methods for assessment of left ventricular shortening and wall stress. J Am Coll Cardiol 1987:9:945-51.

16 Chen QM, Li W, O'Sullivan C, et al. Clinical in vivo calibration of pulse wave tissue Doppler velocities in the assessment of ventricular wall motion. A comparison study with $\mathrm{M}$-mode echocardiography. Int J Cardiol 2004;97:289-95.

17 Pai RG, Bodenheimer MM, Pai SM, et al. Usefulness of systolic excursion of the mitral annulus as an index of left ventricular systolic function. Am J Cardiol $1991 ; 15: 222-4$. 
18 Duncan AM, Francis DP, Henein MY, et al. Limitation of cardiac output by total isovolumic time during pharmacologic stress in patients with dilated cardiomyopathy: activation-mediated effects of left bundle branch block and coronary artery disease. J Am Coll Cardiol 2003;41:121-8.

19 Tei C, Ling LH, Hodge DO, et al. New index of combined systolic and diastolic myocardial performance: a simple and reproducible measure of cardiac function - a study in normals and dilated cardiomyopathy. J Cardiol 1995;26:357-66.

20 Fawzy ME, Awad M, Hassan W, et al. Long-term outcome (up to 15 years) of balloon angioplasty of discrete native coarctation of the aorta in adolescents and adults. J Am Coll Cardiol 2004;43:1062-7.

21 Schrader R, Bussmann WD, Jacobi V, et al. Long-term effects of balloon coarctation angioplasty on arterial blood pressure in adolescent and adult patients. Cathet Cardiovasc Diagn 1995;36:220-5.

22 Sharma UC, Barenbrug P, Pokharel S, et al. Systematic review of the outcome of aortic valve replacement in patients with aortic stenosis. Ann Thorac Surg 2004;78:90-5.

23 Nagueh SF, Mikati I, Kopelen HA, et al. Doppler estimation of left ventricular filling pressure in sinus tachycardia. Circulation 1998;98:1644-50.

24 Heymans S, Schroen B, Vermeersch P, et al. Increased cardiac expression of tissue inhibitor of metalloproteinase- 1 and tissue inhibitor of metalloproteinase-2 is related to cardiac fibrosis and dysfunction in the chronic pressure-overloaded human heart. Circulation 2005;112:1136-44.

25 Julius BK, Spillmann M, Vassalli G, et al. Angina pectoris in patients with aortic stenosis and normal coronary arteries: mechanisms and pathophysiological concepts. Circulation 1997;95:892-8.

26 Meluzin J, Spinarova L, Bakala J, et al. Pulsed Doppler tissue imaging of the velocity of tricuspid annular systolic motion; a new, rapid, and non-invasive method of evaluating right ventricular systolic function. Eur Heart $J$ $2001 ; 22: 280-2$.

27 Dokainish H, Abbey H, Gin K, et al. Usefulness of tissue Doppler imaging in the diagnosis and prognosis of acute right ventricular infarction with inferior wall acute left ventricular infarction. Am J Cardiol 2005;95:1039-42.
28 Boldt J, Kling D, Dapper F, et al. Myocardial temperature during cardiac operations: influence on right ventricular function. J Thorac Cardiovasc Surg 1990;100:562-8

29 Carr-White GS, Kon M, Koh TW, et al. Right ventricular function after pulmonary autograft replacement of the aortic valve. Circulation 1999;100(Suppl):I136-41.

30 Dhillon $\mathbf{R}$, Josen $M$, Henein $M$, et al. Transcatheter closure of atrial septal defect preserves right ventricular function. Heart 2002;87:461-5.

31 Carr JA. The results of catheter-based therapy compared with surgical repair of adult aortic coarctation. J Am Coll Cardiol 2006;47:1101-7.

32 Warnes CA. The adult with congenital heart disease: born to be bad? J Am Coll Cardiol 2005;46:1-8.

33 Gardiner HM, Celermajer DS, Sorensen KE, et al. Arterial reactivity is significantly impaired in normotensive young adults after successful repair of aortic coarctation in childhood, Circulation 1994;89:1745-50.

34 Brili S, Dernellis J, Aggeli C, et al. Aortic elastic properties in patients with repaired coarctation of aorta. Am J Cardiol 1998;82:1140-3.

35 Brili S, Tousoulis D, Antoniades C, et al. Evidence of vascular dysfunction in young patients with successfully repaired coarctation of aorta. Atherosclerosis 2005; 182:97-103.

36 Murakami T, Takeda A. Enhanced aortic pressure wave reflection in patients after repair of aortic coarctation. Ann Thorac Surg 2005;80:995-9.

37 Mancia G, Zanchetti A, Agabiti-Rosei E, et al. Ambulatory blood pressure is superior to clinic blood pressure in predicting treatment-induced regression of left ventricular hypertrophy. SAMPLE Study Group. Study on Ambulatory Monitoring of Blood Pressure and Lisinopril Evaluation. Circulation 1997;95:1464-70.

38 Levy D, Garrison RJ, Savage DD, et al. Prognostic implications of echocardiographically determined left ventricular mass in the Framingham Heart Study. N Engl J Med, 1990 31, 322:1561-6.

39 Vriend JW, Engelfriet PM, de Groot E, et al. Age at repair and left ventricular mass in patients after repair of aortic coarctation. J Thorac Cardiovasc Surg 2005; 130:896-7.

\section{FROM BMJ JOURNALS}

\section{New tests spot heart damage from anabolic steroids}

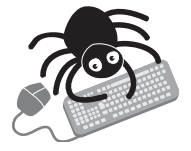

Please visit the Heart website [www.heartinl. com] for a link to the full text of this article.
D octors can now conveniently distinguish early signs of myocardial changes that might herald cardiomyopathy in power athletes who have misused anabolic androgenic steroids.

With Doppler myocardial imaging (DMI) and strain rate imaging (SRI) they have been able to show subclinical impairment of systolic and diastolic function not detectable by standard Doppler echocardiography. Colour DMI analysis disclosed significantly smaller myocardial early diastolic to atrial diastolic wave ratio at the basal interventricular septum (IVS) and left ventricular (LV) lateral wall in steroid misusers than non-users, including controls, and SRI disclosed lower peak systolic strain rate and strain in the middle IVS and LV lateral wall. Lower strain rate in the middle IVS depended on mean dose and duration of steroid use, and impaired LV strain in misusers correlated significantly with reduced performance during physical effort. Standard Doppler echocardiographic analyses were comparable for all subjects.

These results come from age matched male bodybuilders who had been misusing anabolic androgenic steroids for at least five years or had been free of them-45 in all—and 25 sedentary age matched male controls.

The effect of steroid misuse on long term cardiac risk has been hotly debated, but recent observation suggests that locally increased myocardial collagen in athletes under the influence of anabolic steroids might indicate an attempted repair response against myocardial damage.

$\Delta$ D'Andrea A, et al. British Journal of Sports Medicine 2007;41:149-155. 